\title{
ETHIOPIA'S REFUGEES
}

\author{
John Sorenson, University of Manitoba
}

There are approximately two million refugees in the Horn of Africa, most of them Ethiopian. The exact number is hard to judge. The figure could easily double the figure given here. Most estimates do not include the internally displaced or those who are undocumented or outside the mandate of refugee organizations. Despite appalling conditions in many parts of the country, Ethiopia also provides asylum to hundreds of thousands of refugees from the neighbouring countries of Sudan and Somalia. The regional situation is thus a vortex of human misery, with Ethiopia at the centre. While the Horn of Africa gained public attention in the 1980s as famine ravaged the region, the focus of international concern has long since shifted, despite the continuing crisis.

Several factors account for these vast flows of refugees. Most important are the wars which have ravaged Ethiopia for decades. Eritrea, the former Italian colony on the Red Sea coast, was federated with Ethiopia in 1952 and annexed a decade later. Since that time, an armed independence movement has opposed Ethiopia's claim to Eritrea. In the late 1960s, the first waves of Eritrean refugees fled the lowland areas and crossed into Sudan as Emperor Haile Selassie's forces launched a series of attacks on rural villages. These massacres continued into the 1970 s and included the use of napalm and cluster bombs, poisoning of wells and the deliberate targeting of livestock, all designed to deprive the Eritrean Liberation Front (ELF) of support from the local population.

After Haile Selassie was deposed in 1974 by a military junta (known in Amharic as the Derg), repression intensified; in the cities death squads executed suspected Eritrean nationalists. A turning point was reached in 1978, when a massive input of Soviet-supplied weapons allowed the military dictatorship of Mengsitu Haile Mariam to defeat a Somali invasion of the Ogaden region and then turn its full force against Eritrea. At the same time, divisions in the Eritrean movement led to civil war and the eventual emergence of the Eritrean People's Liberation Front (EPLF) as the dominant force. However, the EPLF was largely restricted to the remote northern areas until 1988, when it won substantial victories which appear to have changed the course of the war.

In Tigray, resistance to the central government was sporadic until the formation of the Tigrayan Peoples'

\section{Many refugees in Sudan live in desperate poverty, under appalling conditions and with few opportunities to improve their condition.}

Liberation Front (TPLF) in 1975. Formerly, the TPLF advocated independence but now states its goal as self-determination within a democratic Ethiopia. Following intensification of drought in 1984, the numbers of refugees from Tigray increased dramatically. In $1985,40,000$ Tigrayans who had crossed into Sudan returned home, indicating that economic and environmental conditions were the reason for their original flight. However, refugee movements have continued in response to military and environmental changes and the Derg's forced resettlement program.

By the late 1970s, the Oromo Liberation Front had begun operations in Hararghe, Arsi, Bale and Wollega regions. The Oromo live throughout Ethiopia and are the largest group speaking a mutually intelligible language. When the Emperor Menelik conquered the Oromo in the early part of the century, many Oromo were enslaved and their language and culture were suppressed and replaced with that of the Amhara. The OLF sees itself as fighting an anti-colonial struggle and seeks to establish an independent state, Oromia. In 1976, Oromos fled to Somalia to avoid war between the OLF and the Derg. They were quickly joined by large numbers of ethnic Somalis who fled the Ogaden war and Ethiopian reprisals against the region in 1978.

Ethiopia's refugee crisis is not caused only by wars based on ethnic or national differences. Ecological crisis has also created huge population movements. Large numbers are women, children and older people. Substantial numbers of Amhara refugees have also fled extensive violations of human rights, political repression, forced conscription, environmental disaster and economic crisis in Ethiopia. In some cases, the situation of Amhara refugees may be among the worst. At the Shelembod camp in Somalia, Amhara refugees have been singled out for differential treatment. From 1977 to 1982, the refugees were imprisoned and 500 were then released to the camp under the control of the Ministry of Defence. These refugees were treated as prisoners of war, denied rights to work or talk to foreigners and kept under surveillance while UNHCR was denied access to them. Forced inactivity and despair encouraged psychological deterioration. Although most were moved to Hargeisa in 1985, other refugees remain in isolation.

While considerable numbers of young, urban, educated Ethiopians have fled to the Middle East, Europe and North America, most refugees have fled to Sudan, Somalia, Djibouti and Kenya. As these are among the least developed

Refuge, Vol. 10, No. 4 (April 1991) 
countries, the vast numbers of refugees arriving have a huge impact on these countries. The socio-economic characteristics of the refugees also have specific implications for the host countries. The already-limited opportunities existing in the host countries affect harder on the refugees.

Most refugees are from the rural areas. These groups have crossed the border hurriedly, settled wherever possible and hope to return home. Few facilities are available in the remote areas where many of these people settle. Urban refugees tend to have had a more organized flight from Ethiopia. These individuals are more educated and hope to continue their education or obtain employment; most seek to leave the camps as soon as possible and move to the cities. Here, they compete with the residents for resources and the few existing opportunities for employment. In areas such as Kassala, in Sudan, the facilities are so limited that refugee children are forbidden to attend school. Many refugees in Sudan live in desperate poverty, under appalling conditions and with few opportunities to improve their condition. Serious health and psychological conditions have resulted from overcrowding and unsanitary conditions. Refugee life often forces social changes. Women may be compelled to wear the veil and refrain from work in the fields. Many women are forced into prostitution, a situation which is not only perceived as degrading but which also represents serious health risks, particularly with the spread of AIDS throughout Africa. In some of the camps, the lack of opportunity, overcrowding, boredom, despair, political factionalism, as well as alcohol abuse and prostitution, have transformed life into a nightmare for the inhabitants.

Because of the competition for restricted opportunities and resources, refugees may be brought into conflict with local populations. This applies not only to employment but to pasturage and supplies of water and firewood. Refugees have had an impact on wages as well. Because they have few choices but to work wherever possible, refugees form a pool of cheap labour which tends to drive wages down. Programs intended to benefit refugees may exclude local inhabitants or, in some cases, may benefit local elites most directly. Some areas of eastern Sudan have been subject to a virtually constant flow of refugees for decades. This may result in the refugees being scapegoated; some incidents of violence against refugees have been reported in Sudan.

Fearing such a negative impact, the government of Djibouti exercises a very restricted definition of what constitutes a refugee, insisting that proof of persecution be furnished. In 1983, a repatriation programme sent 150,000 refugees back to Ethiopia. There were many reports that the repatriation was coerced and UNHCR was accused of ignoring human rights abuses. With the publicity surrounding the drought in 1984, the program was temporarily halted, but was resumed in 1986. During one incident at that time, 125 refugees were locked in a metal freight container on a train bound for Ethiopia; six died of suffocation. Although large numbers of refugees have been deported from Djibouti, many keep returning.

Refugee settlement also can have a positive economic influence in the host country. It is widely believed that the Somali government exaggerated the number of refugees living within its borders because of economic benefits it received from international organizations. In 1985, the Somali government claimed that 840,000 refugees were under its protection, despite the fact that UNHCR had reported that nearly half of these had been repatriated to Ethiopia.

Despite the imminence of political change in the Horn of Africa - change which may include the fall of the Derg and the independence of Eritrea - the situation for refugees is unlikely to improve soon. The Derg is determined to fight to the last, and famine looms over the Horn. Up to 11 million people are at risk in southern Sudan and about half that many face starvation in Eritrea and Tigray. As conditions in the region deteriorate, the need for a concerted international effort to address fundamental problems becomes ever more critical.

\section{FROM WATER TO WORLD MAKING}

African Models and Arid Lands

Edited by Gisli Palsson

The Scandinavian Institute of African Studies, Uppsala, 1990

This volume is a valuable collection of essays presented at a work-shop on "Symbols and Resource Management in African Arid lands" held in Helsinki in November, 1989. All the contributors are social anthropologists concerned with the ways in which subsistence producers adapt to extreme environments, i.e. the arid lands in Africa.

As mentioned by the editor, this book focuses on 'how humans make their world in the sense that their reality is inevitably mediated by their cultural context'

Most of the articles deal with pastoral societies in eastern Africa, pointing out their ways of life and their own cultural representation. Two essays throw light on the cultural significance of wells and well-water (Dahl and Mergessa) as well as livestock products (Talle). The cognitive and symbolic dimensions involved by the activity of animal husbandry (Brochdue, Hurskainen) are also emphasized. Other articles deal with major issues each as pastoralism and environmental degradation (Poulsen, Ndagala), the responses of pastoral societies to drought ( $\mathrm{O}^{\prime}$ Leary) or the symbolic identification of an ethnic pastoral group (Salih). All of these articles emphasize the changes pastoral societies have undergone in recent decades.

Apart from pastoralism, two articles are concerned with social change among Mountain farmers (Manger) and cultural representation of fishing among fishermen (Palsson). There are a large number of excellent articles, all based on field work results and full of ethnographic details. Without doubt, this book attempts with success to illuminate the complex interactions between ecology and society and the range of representation developed by human producers.

Reviewed by Veronique Lassailly-Jacob; Centre National de la Recherche Scientifique, Paris, France, and Centre for Refugee Studies, York University, Toronto, Canada. 


\section{BURDEN OR BOOM}

Tom Kuhlman, Amsterdam

VU University Press, 1990 and

\section{ENDURING CRISIS}

Edited by H.J. Tieleman \& T. Kuhlman Leiden, African Studies Centre, 1990

Large numbers of refugees, mainly Eritreans but also Tigrayans, have been moving intoeastern Sudan since the mid1960 's. The region has now become a haven for one of the world's largest refugee concentrations. Despite the duration and extent of the crisis, the situation has received astonishingly little attention from academic researchers. Most information exists in the form of internal reports from government and NGOs. Tom Kuhlman's Burden or Boom and Enduring Crisis, edited by Kuhlman and Tieleman are, therefore, a welcome contribution.

There is considerable overlap between the two books. For example, Kuhlman's contribution to the edited volume is a chapter from his own book, which explains the political background to the refugee crisis. This may disappoint readers who purchase both volumes, but the explanation is succinct and, importantly, corrects the widespread but inaccurate perception of the Eritrean issue as a case of ethnic separatism, so perhaps it bears repeating. Walter Kok's chapter on the economic impact of selfsettled refugees is very useful but some will have read this when it appeared in the Journal of Refugee Studies. Because of the quality of their work, it is disappointing not to have new articles by Kulhman and Kok in this volume.

An anthropological study by Moniek Boerenkamp and Arjan Schuthof raises the very interesting issue of ethnicity among refugees, but remains somewhat general and strikes a rather jarring note by referring to the refugees as 'Baria' rather than Nara. As the authors themselves observe in a footnote, the former means 'slave' in Tigrinya, while the latter is the term the people use for themselves. Similarly, Jan Bouke Wijbrandi's chapter consistently refers to the refugees as 'Ethiopians' while the data indicate the refugees' self- identification as Eritreans. Particularly in the latter instance, because the issue of identity lies at the crux of the refugee situation, the choice of terminology is often seen as a political intervention on its own terms. Nevertheless, a sensitive approach should acknowledge the terms a people apply to themselves. Despite these drawbacks, all the essays in the book are useful and several refer the situation to broader theoretical issues.

Kuhlman's book goes in much greater empirical detail into the economic and social impact of refugees on Kassala and the surrounding area, examining the agrarian sector, labour market, infrastructure and social services. The answer to the question contained in the book's title is a qualified one. Kuhlman suggests that refugees have a positive effect on the economy in the secondary (manufacturing) sector by increasing demand for goods and thereby creating more jobs. However, as Kuhlman acknowledges, this depends on the existence of certain conditions, such as supply of natural resources, capital and functioning economic institutions. Furthermore, the refugees have kept wages low because they are an illegal, thus exploitable, work force. Relief aid is inadequate for subsistence and most refugees must engage in some form of small-scale commercial production or wage labour, but this aid allows refugees to survive by accepting lower wages than Sudanese workers. The refugees are therefore a boon to employers but they are resented by other workers against whom they are placed in competition.

Kulhman concludes that, overall, refugees have had a positive effect on the Sudanese economy and that most refugees are well-integrated economically. This conclusion is somewhat at odds with Kok's assessment, in the edited volume, of an overall negative impact. The researchers do concur in their assessment that there is less a single, specificimpact of refugees but rather differential effects by time, region, and in terms of various social groups. Some elements of Sudanese society have profited from the influx of refugees while others have suffered.
Integration does seem to have been more successful in the Kassala region than in other areas, such as Port Sudan and Gedaref. There is no spatial segregation; severe ethnic conflict is absent and, with certain exceptions, there has been no exclusion of refugees from the labour market. However, it is clear that whatever integration has occurred has taken place in a context in which the majority of the population is desperately poor and the refugees have been concentrated at the lowest level of employment and subsistence. Furthermore, the influx of refugees has to be considered in the broader context. The development policies, which promised to transform the country into the 'bread-basket' of the entire region, have instead wrought environmental havoc and, coupled with corruption, political instability, war and devastating drought, have plunged Sudan into chaos. As the situation throughout the country deteriorates the poorest, including refugees, suffer appalling deprivation; the need for a more appropriate government response, coupled with increased humanitarian aid, is urgent.

The authors demonstrate that refugees are not merely a passive population dependent on aid but rather that they are most industrious. However, they also indicate that the potential economic contributions which refugees can make to Sudan have not been fully utilized. One way in which the situation for refugees could be alleviated, however, would be to legalize their status as workers, thus preventing them from becoming an underprivileged and easily-exploited minority. There is a great need to improve services for refugees, especially in terms of health care, water supply and housing, but policies to deal with the refugee situation must be integrated with appropriate development policies for the region as a whole.

These books both make a significant contribution to understanding the situation of refugees in eastern Sudan and to determining the influence of refugees on the host population.

Reviewed by John Sorenson 